\title{
Prevalence of depressive symptoms and quality of life among patients with diabetes mellitus with and without HIV infection: A South African study
}

\begin{tabular}{|c|c|}
\hline \multicolumn{2}{|c|}{$\begin{array}{l}\text { Authors: } \\
\text { Yonela Qubekile } \\
\text { Saeeda Paruk } \\
\text { Farhanah Paruk } \\
\text { Fa }\end{array}$} \\
\hline \multicolumn{2}{|c|}{$\begin{array}{l}\text { Affiliations: } \\
{ }^{1} \text { Department of Internal } \\
\text { Medicine, Faculty of } \\
\text { Health Science, University } \\
\text { of KwaZulu-Natal, } \\
\text { Durban, South Africa }\end{array}$} \\
\hline \multicolumn{2}{|c|}{$\begin{array}{l}{ }^{2} \text { Department of Psychiatry, } \\
\text { Faculty of Health Science, } \\
\text { University of KwaZulu-Natal, } \\
\text { Durban, South Africa }\end{array}$} \\
\hline \multicolumn{2}{|c|}{$\begin{array}{l}{ }^{3} \text { Department of } \\
\text { Rheumatology, Faculty of } \\
\text { Health Science, University of } \\
\text { KwaZulu-Natal, Durban, } \\
\text { South Africa }\end{array}$} \\
\hline \multicolumn{2}{|c|}{$\begin{array}{l}\text { Corresponding author: } \\
\text { Yonela Qubekile, } \\
\text { yqubekile@yahoo.com }\end{array}$} \\
\hline \multicolumn{2}{|c|}{$\begin{array}{l}\text { Dates: } \\
\text { Received: } 30 \text { June } 2021 \\
\text { Accepted: } 22 \text { Sept. } 2021 \\
\text { Published: } 25 \text { Feb. } 2022\end{array}$} \\
\hline \multicolumn{2}{|c|}{$\begin{array}{l}\text { How to cite this article: } \\
\text { Qubekile Y, Paruk S, Paruk F. } \\
\text { Prevalence of depressive } \\
\text { symptoms and quality of life } \\
\text { among patients with diabetes } \\
\text { mellitus with and without } \\
\text { HIV infection: A South } \\
\text { African study. S Afr J } \\
\text { Psychiat. 2022;28(0), a1762. } \\
\text { https://doi.org/10.4102/ } \\
\text { sajpsychiatry.v28i0.1762 }\end{array}$} \\
\hline \multicolumn{2}{|c|}{$\begin{array}{l}\text { Copyright: } \\
\text { (c) 2022. The Authors. } \\
\text { Licensee: AOSIS. This work } \\
\text { is licensed under the } \\
\text { Creative Commons } \\
\text { Attribution License. }\end{array}$} \\
\hline 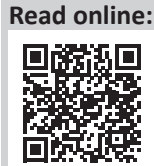 & $\begin{array}{l}\text { Scan this QR } \\
\text { code with your } \\
\text { smart phone or } \\
\text { mobile device } \\
\text { to read online. }\end{array}$ \\
\hline
\end{tabular}

Background: Diabetes mellitus (DM) and human immunodeficiency virus (HIV) infection are both associated with increased risk of mood disorders and poorer quality of life (QOL). This association has not been explored in patients living with comorbid DM and HIV.

Aim: To describe the prevalence of depressive symptoms and impact on the QOL in patients with DM living with and without HIV attending a public sector hospital in South Africa.

Setting: A medical outpatient clinic at a state regional hospital.

Methods: A cross-sectional questionnaire pilot survey was conducted amongst 101 patients with DM attending a specialist medical outpatient service. The assessment was conducted using a structured socio-demographic and clinical questionnaire, the patient health questionnaire 9 (PHQ-9) for depressive symptoms and the World Health Organization QOL scale. The HIV status was confirmed from the clinical records. The correlates of depressive symptomatology in the participants with DM living with and without HIV were identified using $t$-tests.

Results: The prevalence of depressive symptoms in the participants with DM was 36\%. Moderate to severe depression was associated with female gender $(p=0.03)$ and low educational level $(p=0.02)$ but not with HIV comorbidity or clinical characteristics of DM. The QOL was influenced by moderate to severe depressive symptoms (QOL in physical $p<0.218$ and environmental $p<0.001$ domains), but not HIV status $(p=0.218)$.

Conclusion: A substantial proportion of people with DM reported depressive symptoms, which is slightly higher than the average reported in other out-patient studies. The association of depression with poor QOL highlights the need for integrated mental health access in medical outpatient services. The lack of association between comorbid HIV status and DM with depression or QOL needs to be further explored.

Keywords: HIV; type 2 diabetes mellitus; depression; quality of life; South Africa.

\section{Introduction}

South Africa (SA) has one of the highest prevalence rates $(13.7 \%)$ of human immunodeficiency virus (HIV) infections globally, ${ }^{1,2}$ with KwaZulu-Natal (KZN) province having the highest incidence rate in the country. ${ }^{3}$ Longevity amongst people living with HIV (PLWHIV) has increased in the last two decades mainly because of the availability and access to anti-retroviral treatment (ART). In combination with the changes in demographic and environmental factors, this has resulted in behavioural and nutritional transitions that have led to a higher risk of non-communicable diseases (NCDs), including diabetes mellitus (DM) and mental illness. ${ }^{4}$ The prevention and treatment of NCDs are still marginalised in SA because of the overwhelming prevalence of communicable diseases, such as tuberculosis and HIV or acquired immunodeficiency syndrome (AIDS) ${ }^{4}$

The prevalence of DM in adults (20-79 years) in Africa was 4.7\% in 2019, with 19 million living with the condition. This figure is estimated to increase to 47 million by $2045 .{ }^{5}$ South Africa has a higher estimated prevalence of DM than the rest of Africa at $9.3 \%,{ }^{6}$ with a recent study from KZN reporting an even higher prevalence of $14.3 \%$ in the public health sector, the majority of these patients being mainly from the urban district of eThekwini. ${ }^{7}$

Depression affects more than 300 million people globally $(4.4 \%) .^{8}$ The age adjusted rate of depression is higher in the patients with DM (8.3\%) in the United States of America, ${ }^{9}$ whereas 
a Nigerian study found a much higher rate of 30\%. The reasons cited for this variation included lower income levels in Nigeria and the need to provide for a higher number of dependents (children), which resulted in patients being unable to pay for their own healthcare needs. ${ }^{10}$ The prevalence of major depressive disorder in the South African general population is $9.8 \%$, with the lifetime prevalence of depression in KZN being 9\%. ${ }^{11}$ Whilst rates of depressive symptoms vary substantively in different studies, ${ }^{12}$ a $26 \%$ prevalence rate for depressive symptoms was reported in the cross-sectional 2014 South African Social Attitudes Survey of the general population. ${ }^{13}$

A higher prevalence of depression has also been observed amongst PLWHIV ${ }^{14}$ with those at highest risk having not disclosed their seropositive status, lost a loved one, advanced HIV disease stage and being female. ${ }^{14}$ The exact prevalence of depression amongst PLWHIV remains unknown, as studies have generally not used standard diagnostic criteria according to Diagnostic and Statistical Manual (DSM) 5 or International Classification of Diseases (ICD)-10 but have relied on physician reporting or screening surveys. ${ }^{15}$ In contrast, a lower prevalence of depressive symptoms in PLWHIV of $20 \%$ was noted in an Ethiopian study, and the possible reason for this finding was that the participants were stable with immunological recovery. ${ }^{16} \mathrm{~A}$ meta-analysis from East Africa further found depression rates vary greatly and the pooled prevalence of depressive symptoms in PLWHIV was between $12.4 \%$ and $66.14 \%$ depending on the screening or diagnostic tool used. ${ }^{17}$ The prevalence of depressive symptoms was higher in studies using a screening tool compared to diagnostic tool. ${ }^{17}$ In a South African study amongst patients initiating ART, the prevalence of self-reported depressive symptoms was $25 \% .{ }^{18}$ An association was observed between depression and duration of knowledge of HIV sero-positivity (Odds ration $[\mathrm{OR}]=1.02$, confidence interval $[\mathrm{CI}] 1.01-1.03)$, with those belonging to a support group being less likely to be depressed. ${ }^{18}$

\section{The World Health Organization (WHO 1997) defines QoL as:}

$[A] n$ individual's perception of their position in life in the context of the culture and value systems in which they live and in relation to their goals, expectations, standards and concerns. (p. 1)

It is a broad ranging and complex concept that is affected by the individual's physical health, psychological state, personal beliefs, social relationships, and their association with the salient features of their environment. ${ }^{19}$

Although studies show that both HIV and DM are associated with depression and poorer $\mathrm{QoL}^{15}$ this has not been explored in people living with the dual burden of both diseases. This pilot study aims to describe the prevalence of depressive symptoms in out-patients with DM living with and without HIV and explore their QoL. We also sought to describe any associations between depressive symptoms and the participants' socio-demographic and clinical factors. We also described the QoL amongst patients with DM.

\section{Methodology}

A descriptive, cross-sectional study was conducted from January to December 2018 in the adult medical outpatient department at King Edward VIII hospital, eThekwini District, $\mathrm{KZN}$, which offers a regional level specialist service in internal medicine and psychiatry.

\section{Study participants}

Adult patients aged 18 years and older from the medical out-patients with DM on treatment for a minimum of 12 months and living with HIV on treatment for at least 6 months were enrolled after obtaining informed consent. Control patients who were attending the same medical outpatient department, matched for gender, with DM, and who were HIV negative, as per clinical records either tested by ELISA or rapid HIV test (in the last 6 months), and consented, were also enrolled. Patients with other existing chronic medical conditions, such as hypertension and epilepsy, were excluded.

\section{Measures}

A structured questionnaire was used to collect the sociodemographic information (age, gender, marital status, occupation, race, educational level, monthly income, and area of residence). Clinical data on the type of DM (type 1 or 2), DM complications, treatment, and control (glycated hemoglobin levels [HBA1C]) and HIV disease duration, treatment, and markers (CD4 cell count and viral load) within the last 6 months was recorded from the participants' charts.

The Patient Health Questionnaire 9 (PHQ 9) was used which is a validated multipurpose instrument for screening, diagnosing, monitoring and measuring the severity of depression, incorporating DSM-IV diagnostic criteria, to document depressive symptoms. ${ }^{20}$ The PHQ 9 uses a fourpoint Likert scale ( 0 not at all, $1=$ several days, $2=$ more than half the days, 3 = nearly every day) to gauge responses to the questions asking about the respondents' emotional health over the previous 2-week period. Scores on the PHQ 9 can range from 0 to 27 . The scores between 0 and 4 indicate no depression, 5 and 9 mild depression, 10 and 14 moderate depression, 15 and 19 moderately severe depression, and $\geq 20$ severe depression. ${ }^{20}$ Scores of less than 10 seldom occur in individuals with major depression, whilst that of 15 or greater usually signify the presence of major depression. ${ }^{20}$ For this study, 10 was used as the cut-off, as it has an overall sensitivity of $84 \%$ and a poor specificity of $72 \%,{ }^{20}$ the tool having been used in various studies in SA. ${ }^{21,22,23}$

The WHO Quality of Life-BREF (WHOQOL-BREF) is a person-centred instrument for subjective assessment and based on a cross culturally sensitive concept. It consists of a 
number of QOL items that are concerned with the meaning of different aspects of life and how satisfactory or problematic their experience is of them. The WHOQOL-BREF is an abbreviated 26 item version of the WHOQOL-100 that contains one item from each of the 24 facets of QOL, included in the WHOQOL-100, plus two benchmark items from the general facet on the overall QOL and general health. The WHOQOL-BREF is scored in four domains that include physical health, psychological, social relations and environmental domains, and has been used in several South African studies. ${ }^{24,25}$

All interviews were conducted by the principal investigator (PI) after obtaining written informed consent. The PI is bilingual and conducted interviews in English and IsiZulu, with the tools being available in both.

\section{Sample size}

The required sample size calculated was 50 patients with DM and HIV and 50 as a control with DM and no HIV. The statistical parameters used to calculate the sample size were effect size $=0.57$ (medium), type $\mathrm{I}(\alpha)$ error $=0.05$ (the probability of falsely rejecting the null hypothesis $=5 \%$ ), and type II $(\beta)$ error $=0.2$ (the probability of falsely retaining the null hypothesis). Statistical power $=1-\beta-1-0.2=0.8$ (statistical power of $80 \%$ ).

\section{Data analysis}

Descriptive statistics were used to describe the population frequency and per cent to describe categorical variables. The frequency distributions of numeric variables were examined, and means with standard deviation or medians and interquartiles ranges were used as appropriate. The two groups were compared using the student $t$-test, whilst the categorical variables were compared using Pearson's chi square test and Fisher chi square test. A significance of $p<0.05$ was used for statistical significance testing, with the data being analysed using programme $\mathrm{R}$ version.

\section{Ethical considerations}

Ethical approval for this study (BE553/17) was granted by the Biomedical Research Ethics Committee of the University of KwaZulu-Natal. Approval was obtained from the hospital and KZN provincial Department of Health. Those reporting psychological distress/requesting mental healthcare support/ with moderate to severe depression were referred to the psychiatry services at the hospital.

\section{Results}

A total of 101 individuals participated and four refused to participate, of whom one was living with HIV and three were HIV negative. Their reasons for not participating included lack of time or other commitments. The socio-demographic and clinical characteristics of the participants with DM living with and without HIV are described in Table 1 . The median age of all the participants was 54.5 (interquartile range [IQR] 48-61.3) years. The female to male ratio was 1.7:1 and most of the participants were black people (83\%). People living with HIV were more likely to be younger $(p<0.001)$, black people $(96 \%, p<0.001)$, married $(58 \%, p=0.003)$, more than twothirds lived in a township $(p=0.008)$.

There were no significant differences in the type of DM, DM disease duration, treatment or control, as assessed by glycated haemoglobin level between the PLWHIV and the HIV negative group. Complications related to DM were similar between the two groups, except for cerebrovascular accidents, which were higher in the HIV negative than the PLWHIV group $(16 \%$ vs. $3 \%, p=0.031)$. Peripheral neuropathy was only found in PLWHIV and DM (14\%, $p=0.012)$.

\section{Prevalence of depressive symptoms}

A previous psychiatric history was reported in eight (8\%) participants of whom six (6\%) were PLWHIV and two (2\%) were HIV negative $(p=1.00)$. Sixty-four $(63.3 \%)$ participants reported no to minimal depressive symptoms on PHQ 9 (0-4 score), whilst 24 (23.7\%) reported mild (PHQ score 5-9) and $12(11.8 \%)$ reported moderate to severe symptoms (PHQ score 10 or greater). There was no difference in PLHIV and HIV-negative patients in terms of severe depressive symptoms $(p=0.218)$.

The HIV comorbidity amongst people living with DM and its clinical variables, such as type and complications or control, as assessed by the HBA1C, was not significantly associated with an increased risk of moderate to severe depressive symptoms. However, female gender $(p=0.03)$ and those with lower educational level $(p=0.02)$ were more likely to have moderate to severe depressive symptoms

For the PLWHIV, the median years since HIV diagnosis was five (IQR 3-9), median CD4 cell count was 492 cells $/ \mathrm{mm}^{3}$ (IQR 240-695) and 39 (78\%) had a suppressed viral load. Forty-two (84\%) PLWHIV were on first line ART regimen, which included Abacavir + lamuvidine + efaverens $3(6 \%)$, Zidovudine + lamuvidine + efaverens one (2\%), Tenofovir + emtricitabine + efaverens 38 (76\%), and eight (16\%) were on second line/other ART regimens. As only four PLWHIV who were all virologically suppressed and on three different regiments had a PHQ 9 score of greater than 10, we did not explore variables such as CD4 cell count, viral load, antiretroviral treatment and treatment duration as sub-groups made analysis difficult because of the limited sample sizes.

Table 2 summarises the data comparing the participants with DM with no or mild depressive symptoms to those with moderate to severe depressive symptoms and their associations with socio-demographic and clinical factors, including comorbid HIV status, which was not statistically significant. 
TABLE 1: Socio-demographic and clinical characteristics of patients with diabetes mellitus with and without human immunodeficiency virus infection $(n=100)$.

\begin{tabular}{|c|c|c|c|c|c|c|c|}
\hline \multirow[t]{2}{*}{ Variables } & \multicolumn{2}{|c|}{ Total } & \multicolumn{2}{|c|}{ HIV negative } & \multicolumn{2}{|c|}{ HIV positive } & \multirow[t]{2}{*}{$p$} \\
\hline & $n$ & $\%$ & $n$ & $\%$ & $n$ & $\%$ & \\
\hline Age (years) $\dagger$ & 54.5 & $48.8-61.3$ & 59 & $51.3-65$ & 51 & $47.3-55$ & $<0.001$ \\
\hline Gender & & & & & & & 0.534 \\
\hline Men & 37 & 37 & 17 & 34 & 20 & 40 & \\
\hline Women & 63 & 63 & 33 & 66 & 30 & 60 & \\
\hline Race & & & & & & & $<0.001$ \\
\hline Other & 17 & 17 & 15 & 30 & 2 & 4 & \\
\hline Marital status & & & & & & & 0.003 \\
\hline Single & 34 & 34 & 17 & 34 & 17 & 34 & \\
\hline Married & 45 & 45 & 16 & 32 & 29 & 58 & \\
\hline Divorced/Widowed & 21 & 21 & 17 & 34 & 4 & 8 & \\
\hline Residence & & & & & & & 0.008 \\
\hline Urban & 39 & 39 & 24 & 48 & 15 & 30 & \\
\hline Township & 49 & 49 & 17 & 14 & 32 & 64 & \\
\hline Education & & & & & & & 0.146 \\
\hline Grade 1-7 & 15 & 11 & 11 & 22 & 4 & 8 & \\
\hline Grade $8-12$ & 72 & 72 & 33 & 66 & 39 & 78 & \\
\hline Tertiary & 13 & 13 & 6 & 12 & 7 & 14 & \\
\hline Occupation & & & & & & & 0.056 \\
\hline Employed & 33 & 33 & 12 & 24 & 21 & 42 & \\
\hline Unemployed & 67 & 67 & 38 & 76 & 29 & 58 & \\
\hline Income & & & & & & & 0.041 \\
\hline$<$ R1000 & 12 & 12 & 4 & 8 & 8 & 16 & \\
\hline R1001-R2500 & 50 & 50 & 31 & 62 & 19 & 38 & \\
\hline R2501-R5000 & 13 & 13 & 3 & 6 & 10 & 20 & \\
\hline R5001-R10 000 & 14 & 14 & 5 & 10 & 9 & 18 & \\
\hline R10 000+ & 11 & 11 & 7 & 14 & 4 & 8 & \\
\hline Type 2 & 88 & 88 & 43 & 86 & 45 & 90 & \\
\hline Diabetes duration (years) $\dagger$ & 6 & $3-11$ & 6 & $3-11$ & 6 & $3-12$ & 0.730 \\
\hline DM Cardiac & 15 & 15 & 9 & 18 & 6 & 12 & 0.401 \\
\hline Complications CVA & 9 & 9 & 8 & 16 & 1 & 2 & 0.031 \\
\hline Nephropathy $\ddagger$ & 22 & 22 & 14 & 28 & 8 & 16 & 0.161 \\
\hline Retinopathy & 7 & 7 & 2 & 4 & 3 & 6 & 0.436 \\
\hline Peripheral neuropathy & 7 & 7 & 0 & 0 & 7 & 14 & 0.012 \\
\hline Treatment & & & & & & & 0.451 \\
\hline Insulin & 36 & 36 & 21 & 42 & 15 & 30 & \\
\hline Oral & 47 & 47 & 21 & 42 & 26 & 52 & \\
\hline Dual & 17 & 17 & 8 & 16 & 9 & 18 & \\
\hline $\mathrm{HbA} 1 \mathrm{C} \uparrow(\mathrm{mmoL} / \mathrm{L})$ & 7.8 & $6.6-99$ & 7.8 & $6.6-9.4$ & 7.7 & $6.6-10.5$ & 0.461 \\
\hline
\end{tabular}

DM, diabetes mellitus; CVA, cerebrovascular accident; HbA1C, glycated hemoglobin $1 \mathrm{C}$.

$\dagger$, median (IQR); $\$$, Nephropathy: Estimated glomerular filtration rate $<60 \mathrm{~mL} / \mathrm{min} / 1.73 \mathrm{~m} 2$ (Modification of diet in renal disease study equation).

\section{Quality of life and association with depressive symptoms}

The WHO QoL BREF score for each domain did not differ significantly between the PLWHIV and HIV-negative participants, as noted in Table 3. However, those who had moderate to severe depressive symptoms had a poorer QOL in the physical and environmental domains compared to those with no or mild depressive symptoms, as summarised in Table 4.

\section{Discussion}

This is a pilot case control study from SA to determine the prevalence of depressive symptoms in patients with DM living with and without HIV and the impact of depressive symptoms on the QOL. The study's key findings are that at least one-third (36\%) of the participants with DM reported depressive symptoms, which were mainly undetected. Whilst comorbid HIV infection in DM (type, complications or control) was not associated with moderate to severe depressive score, moderate to severe depressive symptoms were associated with gender, educational level and poorer QOL (physical and environmental domains) amongst all people with DM.

The prevalence of depression in our study was higher than that reported in the South African general population at $9.7 \%$ for lifetime and $4.9 \%$ for the 12 months prior to 
TABLE 2: Association of depressive symptom score with socio-demographic and clinical variables of diabetes mellitus and human immunodeficiency virus $(n=100)$.

\begin{tabular}{|c|c|c|c|c|c|c|c|}
\hline \multirow[t]{2}{*}{ PHQ-9 total score } & \multicolumn{2}{|c|}{ Total } & \multicolumn{2}{|c|}{$P H Q \leq 9.9$} & \multicolumn{2}{|c|}{$\mathrm{PHQ} \geq 10$} & \multirow[t]{2}{*}{$p$} \\
\hline & $n$ & $\%$ & $n$ & $\%$ & $n$ & $\%$ & \\
\hline Age (mean $\pm S D$ ) years & 53.7 & 11.1 & 53.3 & 11.2 & 56.6 & 10.6 & 0.343 \\
\hline Gender & & & & & & & 0.030 \\
\hline Male & 37 & 37 & 36 & 40.9 & 1 & 8.3 & \\
\hline Female & 63 & 63 & 52 & 59.1 & 11 & 91.7 & \\
\hline Marital status & & & & & & & 0.172 \\
\hline Single & 34 & 34 & 32 & 36.4 & 2 & 16.7 & \\
\hline Married & 45 & 45 & 40 & 45.5 & 5 & 41.7 & \\
\hline Divorced/widowed & 21 & 21 & 16 & 18.2 & 5 & 41.7 & \\
\hline Occupation & & & & & & & 0.327 \\
\hline Employed & 33 & 33 & 31 & 35.2 & 2 & 16.7 & \\
\hline Unemployed & 67 & 67 & 57 & 64.8 & 10 & 83.3 & \\
\hline Race & & & & & & & 0.424 \\
\hline Black people & 83 & 83 & 74 & 84.1 & 9 & 75 & \\
\hline Education & & & & & & & 0.020 \\
\hline Grade 1-7 & 15 & 15 & 10 & 11.4 & 5 & 41.7 & \\
\hline Level Grade 8-12 & 72 & 72 & 65 & 73.9 & 7 & 58.3 & \\
\hline Tertiary education & 13 & 13 & 13 & 14 & 0 & 0 & \\
\hline Income & & & & & & & 0.406 \\
\hline Under R1000 & 12 & 12 & 10 & 11.4 & 2 & 16.7 & \\
\hline R1001-R2500 & 50 & 50 & 44 & 50 & 6 & 50 & \\
\hline R2501-R5000 & 13 & 13 & 10 & 11.4 & 3 & 25 & \\
\hline R5001-R10 000 & 14 & 14 & 14 & 15.9 & 0 & 0 & \\
\hline R10 000+ & 11 & 11 & 10 & 11.4 & 1 & 8.3 & \\
\hline DM & & & & & & & 0.351 \\
\hline Type 1 & 12 & 12 & 12 & 13.6 & 0 & 0 & \\
\hline Type 2 & 88 & 88 & 76 & 86 & 12 & 100 & \\
\hline Treatment & & & & & & & 0.503 \\
\hline Dual & 17 & 17 & 15 & 17 & 2 & 17 & \\
\hline Duration of DM (years) $\dagger$ & 6 & $3-11$ & 6 & $3-11$ & 10 & $3-11$ & 0.608 \\
\hline $\mathrm{HbA1c}(\mathrm{mmoL} / \mathrm{L}) \dagger$ & 7.8 & $6.6-10$ & 7.7 & $6.6-9.8$ & 8.6 & $7.6-11.2$ & 0.168 \\
\hline DM Cardiac & 15 & 15 & 13 & 15 & 2 & 17 & 1.000 \\
\hline Complications CVA & 9 & 9 & 7 & 8 & 2 & 17 & 0.294 \\
\hline Nephropathy & 22 & 22 & 19 & 22 & 3 & 25 & 0.713 \\
\hline Retinopathy & 7 & 7 & 6 & 7 & 1 & 8 & 1.000 \\
\hline Peripheral neuropathy & 7 & 7 & 7 & 8 & 0 & 0 & 0.594 \\
\hline HIV status & & & & & & & 0.218 \\
\hline Negative & 50 & 50 & 42 & 48 & 8 & 67 & \\
\hline Positive & 50 & 50 & 46 & 52 & 4 & 33 & \\
\hline
\end{tabular}

DM, diabetes mellitus; CVA, cerebrovascular accident; PHQ, Patient Health Questionnaire; SD, standard deviation; HbA1C, glycated hemoglobin 1C.

$\dagger$, median (IQR).

TABLE 3: Association of quality of life in patients with diabetes mellitus with and without human immunodeficiency virus infection.

\begin{tabular}{|c|c|c|c|c|c|c|c|}
\hline \multirow[t]{2}{*}{ QOL sub-domains } & \multicolumn{2}{|c|}{ Total } & \multicolumn{2}{|c|}{ DM \& HIV negative } & \multicolumn{2}{|c|}{ DM \& HIV positive } & \multirow[t]{2}{*}{$p$} \\
\hline & $n$ & $\pm S D$ & $n$ & $\pm S D$ & $n$ & $\pm S D$ & \\
\hline Total physical $\dagger$ & 23.6 & 5.6 & 23 & 6 & 24.1 & 5.2 & 0.592 \\
\hline Total psychological $\dagger$ & 20.2 & 2.4 & 20.6 & 2.6 & 19.9 & 2.2 & 0.592 \\
\hline Total environmental $\dagger$ & 27 & 4.9 & 26.9 & 5.7 & 27.6 & 3.9 & 0.766 \\
\hline Total social $\uparrow$ & 7.5 & 1.5 & 7.6 & 1.6 & 7.42 & 1.4 & 0.161 \\
\hline
\end{tabular}

$\dagger$, mean ( \pm SD).

interview. ${ }^{26}$ A recent study similarly showed a much higher prevalence of depression (46\%) amongst patients with type $2 \mathrm{DM}$ attending a specialist diabetic clinic, which again suggests vulnerability to depressive symptoms amongst this group. ${ }^{23}$ Reasons for the variation in the prevalence of depression may include use of different measurement tools and cut-off points. ${ }^{27}$
The current study finding, that depressive symptoms were associated with female gender and lower educational level, is supported by the literature. ${ }^{8,23,28}$ Tomlinson and colleagues showed that the prevalence of depression was much higher amongst females, who were 1.75 times more likely to experience lifetime depression than males, and was significantly higher amongst those with low level of 
TABLE 4: Association between depressive symptom score (patient health questionnaire 9) and quality of life in total cohort of patients with diabetes mellitus with and without HIV infection.

\begin{tabular}{|c|c|c|c|c|c|c|c|}
\hline \multirow[t]{2}{*}{ QOL domains score } & \multicolumn{2}{|c|}{ Total } & \multicolumn{2}{|c|}{$\mathrm{PHQ} \leq 9$} & \multicolumn{2}{|c|}{$P H Q \geq 10$} & \multirow[t]{2}{*}{$p$} \\
\hline & $n$ & $\pm S D$ & $n$ & $\pm S D$ & $n$ & $\pm S D$ & \\
\hline Total physical† & 23.6 & 5.6 & 24.5 & 4.9 & 16.4 & 5.8 & $<0.001$ \\
\hline Total psychological $\dagger$ & 20.2 & 2.4 & 20.5 & 2.2 & 18.1 & 2.9 & 0.005 \\
\hline Total social $\dagger$ & 7.5 & 1.5 & 7.7 & 1.4 & 6.6 & 2 & 0.092 \\
\hline Total environmental $\dagger$ & 27.3 & 4.9 & 28 & 4.4 & 22.1 & 5.3 & $<0.001$ \\
\hline
\end{tabular}

$\dagger$, mean ( \pm SD).

education. ${ }^{26}$ The Hunt study examined if a higher educational level protects against anxiety and/or depression and if this protection accumulates with time. The results showed that low educational levels were significantly associated with depression, whilst higher educational levels had a protective effect that accumulates throughout life. ${ }^{29}$

The findings of this pilot study failed to establish any association between depressive symptoms and clinical features of HIV or DM, which suggest that they may not be the most pressing risk factors in individuals receiving chronic specialist medical care, and that socio-demographic factors, such as gender and educational level, remain driving factors that influence mood disorders. There is welldocumented evidence to support the interaction and outcomes between DM and depression, which is mediated by social contexts, especially amongst low-income countries. ${ }^{30}$ Whilst Tesfaw and colleagues found that patients with stage III HIV were more likely to be depressed, they also identified that psycho-social factors, such as HIV stigma, poor social support and poor medicine adherence, increased the risk of depression. ${ }^{31}$ A Nigerian study found that $56 \%$ of PLWHIV had depressive symptoms, which these were also associated with psycho-social factors, such as female gender, below average schooling and poor economic status. ${ }^{28}$ This suggests the need to consider providing additional psychosocial support and mental health care access for the most vulnerable in our communities.

The association of QoL with the PHQ-9 score showed statistical differences in the physical and environmental domains, which suggests that comorbidity of HIV and DM was not impacting on QoL, but that mental health problems were. These findings are consistent with a previous study, which showed that all four domains of QoL were associated with depression in patients with Type 2 DM. ${ }^{32}$ Deshmuck and colleagues also noted that in PLWHIV, depression was associated with significantly lower QoL, particularly in the social and environmental domains. ${ }^{33}$ An Indonesian study reported a strong correlation of higher depression scores associated with lower QoL in PLWHIV. ${ }^{34}$ Finally, a study conducted in Uganda reported that although QoL improved over time for PLWHIV, it was associated with depression, low education level and female gender. ${ }^{35}$ Thus, it is essential to screen and treat underlying mood disorders in patients with a medical disorder, as it could be impacting on the QoL. The use of a simple screening tool, such as the PHQ 9, could be an initial important step towards addressing issues related to QOL.

\section{Limitations}

The study has some limitations because of the fact that it took place at a single clinical site with a small sample size, which limits its generalisability, although it provides a snapshot of the current clinical public sector characteristics of patients with DM living with and without HIV. The study is urbanand hospital-based, so the findings may not be generalisable to other settings, and relies on self-reporting of symptoms, with the potential for patients under/over reporting symptoms. In addition, the poor specificity and sensitivity of PHQ 9 for depression is noted when using a cut-off score of 10 on this screening tool. There is a need for a longitudinal larger community-based study to further explore the factors associated with depressive symptoms in this population.

\section{Conclusion}

The high prevalence of undetected depressive symptoms associated with gender and educational level, and that those with depression reported poorer QOL in two domains amongst patients with DM with and without HIV, highlight the importance of diagnosing and treating for underlying mood disorders in patients with chronic medical illnesses. This indicates the need for efficient mental healthcare interventions to be integrated into routine clinical care in medical outpatient services to treat the person, and not just their medical condition.

\section{Acknowledgements}

We are grateful to the patients who participated and the hospital staff who helped with this study.

\section{Competing interests}

The authors declare that they have no financial or personal relationships that may have inappropriately influenced them in writing this article.

\section{Authors' contributions}

Y.Q.: Study concept and design, acquisition of patients and/or data analysis, interpretation of data, and preparation of manuscript. S.P.: Study concept and design, analysis and interpretation of data, and preparation of manuscript. F.P.: Study concept and design, analysis and interpretation of data, and preparation of manuscript. 


\section{Funding information}

This research received no specific grant from any funding agency in the public, commercial or not-for-profit sectors.

\section{Data availability}

Data are available from the corresponding author, Y.Q., upon special request.

\section{Disclaimer}

The views and opinions expressed in this article are those of the authors and do not necessarily reflect the official policy or position of any affiliated agency of the authors.

\section{References}

1. Joint United Nations Programme on HIV/AIDS. UNAIDS.org. [Online]. 2018 [cited 2020 May]. Available from: https://www.unaids.org/en/resources/presscentre/ featurestories/2018/november/pcb-field-visit-south-africa

2. Statistics South Africa. Statssa: Mid-year population estimates, 2021 Statistics South Africa [homepage on the Internet]. 2021 [cited 2021 Sept 06]. Available from: www.statssa.gov.za/publications/P0302/P03022021.pdf

3. Human Science Research Council. The fifth South African national HIV prevalence, incidence, behaviours and communication survey, 2017: HIV impact assessment summary report. Cape Town: Human Science Research Council; 2018.

4. Mayosi B, Flisher A, Lallo $U$, et al. The burden of non-communicable diseases in South Africa. Lancet. 2009;374(9693):934-947. https://doi.org/10.1016/S01406736(09)61087-4

5. International Diabetes Federation. IDF Diabetes Atlas. Brussels: International Diabetes Federation; 2019.

6. Peer N, Kengne A, Motala A, et al. Diabetes in the African region: An update. Diabetes Res Clin Pract. 2014;103(2):197-205. https://doi.org/10.1016/j.diabres.2013.11.006

7. Sahadew N, Singaram V, Brown S. Distribution, incidence, prevalence and default of patients with diabetes mellitus accessing public healthcare in the 11 districts of KwaZulu-Natal, South Africa. S Afr Med J. 2016;106(4):389. https://doi. org/10.7196/SAMJ.2016.v106i4.10143

8. World Health Organization. World Health Organization: Depression and other common mental disorders: Global estimates [homepage on the Internet]. 2017 [cited 2017 June 24]. Available from: http://www.who.int/iris/handle/10665/254610

9. Li C, Ford E, Strine T, et al. Prevalance of depression amongst U.S adults with diabetes: Findings from the 2006 behavioral risk surveilance system. Diabetes Care. 2008;31(1):105-107. https://doi.org/10.2337/dc07-1154

10. James B, Omoaregba J, Eze G, et al. Depression amongst patients with diabetes mellitus in a Nigerian teaching hospital. S Afr J Psychiatr. 2010;16(2):4. https://doi. org/10.4102/sajpsychiatry.v16i2.232

11. Herman A, Stein D, Seedat $S$, et al. The South African stress and health (SASH) study: $12-$ month and lifetime prevalence of common mental disorder. S Afr Med J. 2009;99(5 Pt 2):339-344.

12. Wang J, Wu X, Lai W, et al. Prevalence of depression and sepressive symptoms amongst outpatients: A systemic review and meta-analysis. BMJ Open. 2017;7(8):e017173. https://doi.org/10.1136/bmjopen-2017-017173

13. Mutyambizi C, Booysen F, Stornes $P$, et al. ubjective social status and inequalities in depressive symptoms: A gender-specific decomposition analysis for South Africa. Int J Equity Health. 2019;18:87. https://doi.org/10.1186/s12939-019-0996-0

14. Dube B, Benton T, Cruess D, et al. Neuropsychiatric manifestations of HIV infection and AIDS. J Psychiatry Neurosci. 2005;30(4):237-246.

15. Klinkenberg W, Sacks S, for the HIV/AIDS Treatment Adherence. Mental disorders and drug abuse in oersons living with HIV/AIDS. AIDS Care. 2004;16(Supp 1):22-24. https://doi.org/10.1080/09540120412331315303
16. Seid S, Abdu O, Mitiku M, Tamirat K. Prevalence of depression and associated factors amongst HIV/AIDS patients attending antiretroviral therapy clinic at Dessie referral hospital, South Wollo Ethiopia. Int J Ment Health Syst. 2020;14:55. https://doi.org/10.1186/s13033-020-00389-0

17. Ayano G, Solomon M, Abraha M. A systematic review and meta-analysis of epidemiology of depression in people living with HIV in east Africa. BMC Psychiatr. 2018;18:254. https://doi.org/10.1186/s12888-018-1835-3

18. Pappin M, Wouters E, Booysen F. Anxiety and depression amongst patients enrolled in a public sector antiretroviral treatment programme in South Africa: A cross-sectional study. BMC Public Health. 2012;12(1):1-9. https://doi. org/10.1186/1471-2458-12-244

19. WHOQOL group. World Health Organization: measuring quality of life. [Online]. Geneva; 1997. WHOQOL: [cited 2021 May 24] Available from: https://apps.who. int/iris/handle/10665/63482

20. Kroenke K, Spitzer R, Williams J. The PHQ-9: Validity of a brief depression severity measure. J Gen Intern Med. 2001;16(9):606-613. https://doi. org/10.1046/j.1525-1497.2001.016009606.x

21. Bhana A, Rathod S, Selohilwe $O$, et al. The validity of the patient healh questionnaire for screening depression in chronic care patients in primary health care in South Africa. BMC Psychiatr. 2015;15:118. https://doi.org/10.1186/ s12888-015-0503-0

22. Cholera R, Gaynes B, Pence B, et al. Validity of the patient health questionnaire- 9 to screen for depression in a high burden primary healthcare clinic in Johannesburg, South Africa. J Affect Disord. 2014;167:160-166. https://doi. org/10.1016/j.jad.2014.06.003

23. Van Vuuren J, Pillay S. Major depressive disorder in patients with diabetes in Pietermaritzburg, South Africa. S Afr Med J. 2018;109(1):58. https://doi. org/10.7196/SAMJ.2018.v109i1.13356

24. Mapatwana D, Tomita A, Burns J, et al. Predictors of quality of life amongst community psychiatric patients in a peri-urban district of Gauteng Province, South Africa. Int J Soc Psychiatr. 2019;65(4):322. https://doi. org/10.1177/0020764019842291

25. Nlabathi S, Parker J, Chiliza B, et al. The burden of care, quality of life and depression in relatives of patients with serious mental illness treated at Lentegeur Hospital, South Africa. S Afr J Psychiatr. 2018;24:a1312. https://doi.org/10.4102/ sajpsychiatry.v24i0.1312

26. Tomlison M, Grimsurud A, Stein D, et al. The epidemiology of major depression in South Africa: Results from the South African Stress and Health study. S Afr Med J. 2009;99(5 Pt 2):367-372.

27. Bernad C, Dabis F, De Rekeneire N. Prevalence and factors associated with depression in people living with HIV in sub-Saharan Africa: A systematic review and meta-analysis. PLoS One. 2017;12(8):e0181960. https://doi.org/10.1371/ and meta-analysis. $\mathrm{PL}$

28. Issa B, Olanrewaju G. Prevalence amd correlates of depressive disorders amongst people living with HIV/AIDS, in North Central Nigeria. J AIDS Clin Res. 2013:4:11. https://doi.org/10.4172/2155-6113.1000251

29. Bjelland I, Krokstad S, Mykletun A, et al. Does a higher educational level protect against anxiety and depression? The HUNT study. Soc Sci Med. 2008;66(6):1334-1345. https://doi.org/10.1016/j.socscimed.2007.12.019

30. Lund C, Breen A, Flisher AJ, et al. Poverty and common mental disorders in low and middle income countries: A systemic review. Soc Sci Med. 2010;71(3):517528. https://doi.org/10.1016/j.socscimed.2010.04.027

31. Tesfaw G, Ayano G, Awoke T, et al. Prevalence and correlates of depression and anxiety amongst patients with HIV on-follow up at Alert Hospital, Addis Ababa, Ethopia. BMC Psychiatr. 2016;16:368. https://doi.org/10.1186/s12888-0161037-9

32. Ibrahim E, Ozlem E, Mehmet S. The effects of depression on qiality of life of patients with type II diabetes mellitus. Depress Anxiety. 2008;25(2):98-106.

33. Deshmukh N, Borkar A, Deshmukh J. Depression and its associated factors amongst people with HIV/AIDS: Can it affect their quality of life? J Fam Med Prim Care. 2017;6(3):549. https://doi.org/10.4103/2249-4863.222016

34. Siregar M, Abdullah V, Mamfaluti T. Correlation of depression and quality of life in HIV/AIDS patients. Earth Environ Sci. 2018;125:012009. https://doi. org/10.1088/1755-1315/125/1/012009

35. Mutabazi-Mwesigire $D$, Katamba A, Martin $F$, et al. Factors that affect quality of life amongst people living with HIV attending an urban clinic in Uganda: A cohort study. PLoS One. 2015;10(6):e0126810. https://doi.org/10.1371/journal. pone.0126810 